\title{
Homogentisic acid-based whole-cell biosensor for detection of alkaptonuria disease
}

Rajat Dhyani, Krishna Shankar, Ankita Bhatt, Shubham Jain, Ajmal Hussain, Naveen Kumar Navani,*

Chemical Biology Laboratory, Department of Biotechnology, Indian Institute of Technology Roorkee, Roorkee, 247667, Uttarakhand, India

* Corresponding Author.

E-mail address - naveen.navani@bt.iitr.ac.in (Naveen Kumar Navani) 


\section{Contents}

1. Design principle of homogentisic acid biosensor for detection of alkaptonuria disease.........S3

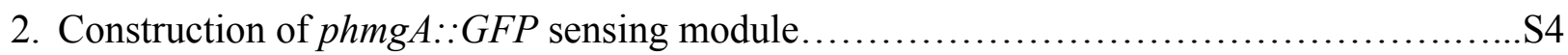

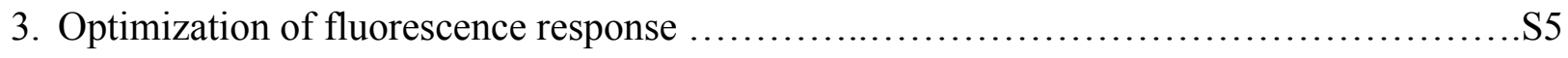

4. Comparison between wild type and Tn::hmgA

Fluorescence response to homogentisic acid................................... 6

5. Comparison of limit of detection of whole cell-based biosensor

with various other analytical techniques currently in use............................ 7

6. Linear response of homogentisic acid quantified through whole-cell biosensor and

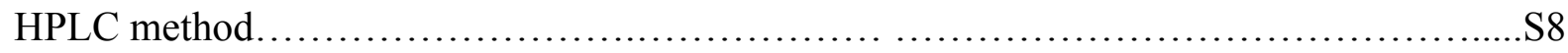

7. Detection precision for quantification of homogentisic acid

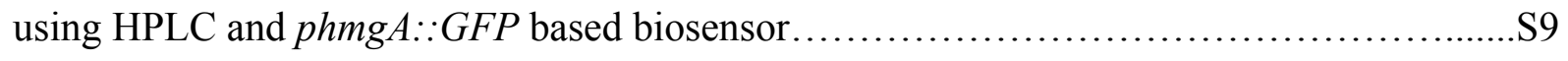

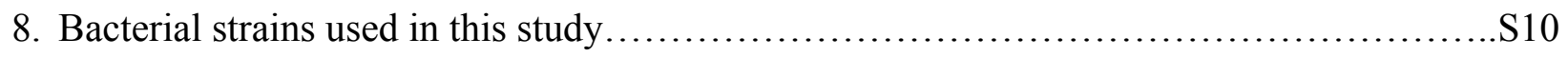

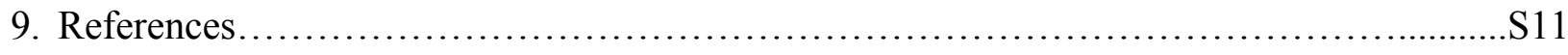


1. Design principle of whole-cell biosensor strategy for the detection of homogentisic acid in an alkaptonuria patient

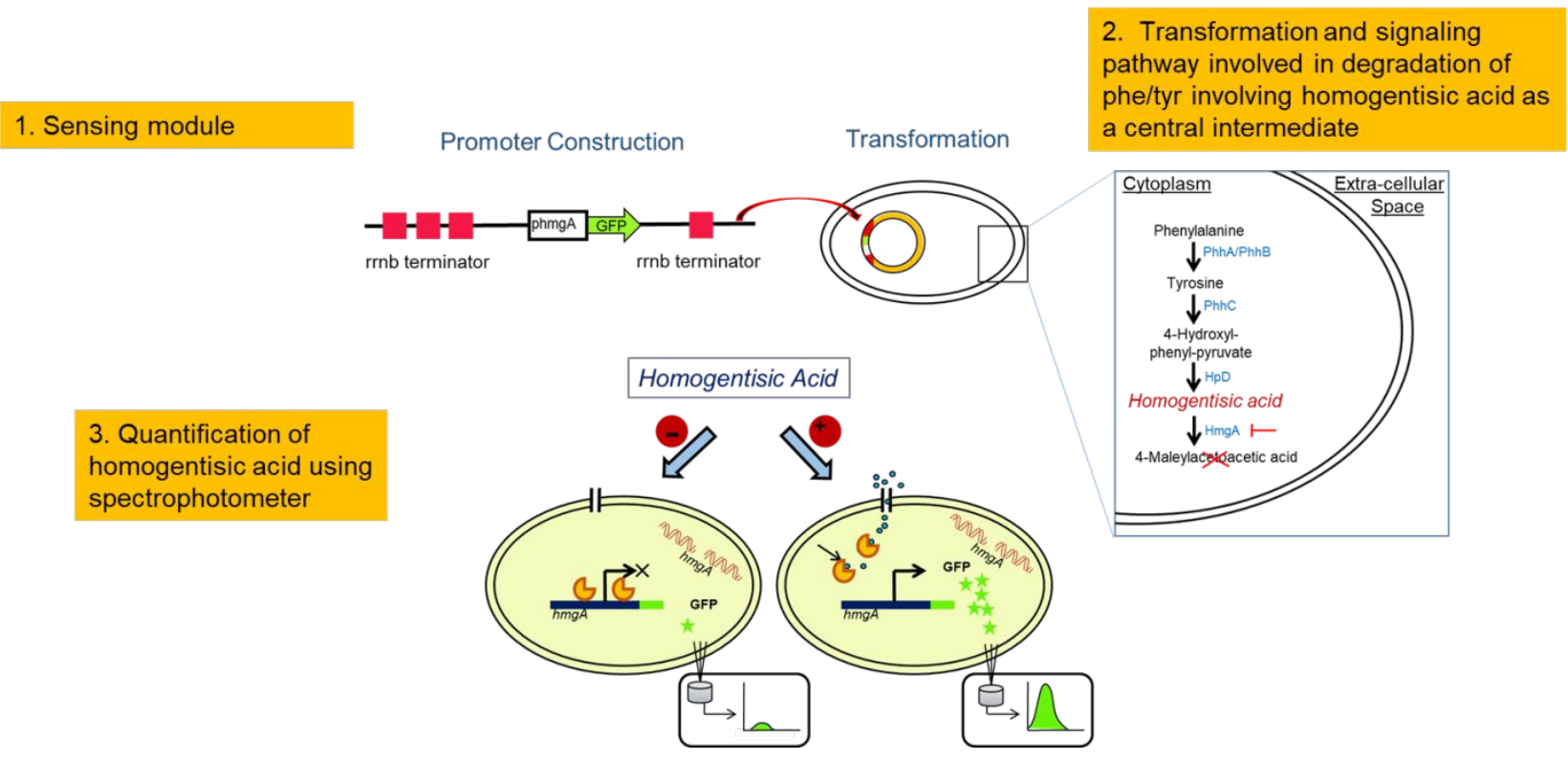

Fig. S1. Schematic illustration representing whole-cell biosensor for the detection of homogentisic acid in alkaptonuria patients. 


\section{Construction of phmgA::GFP plasmid}

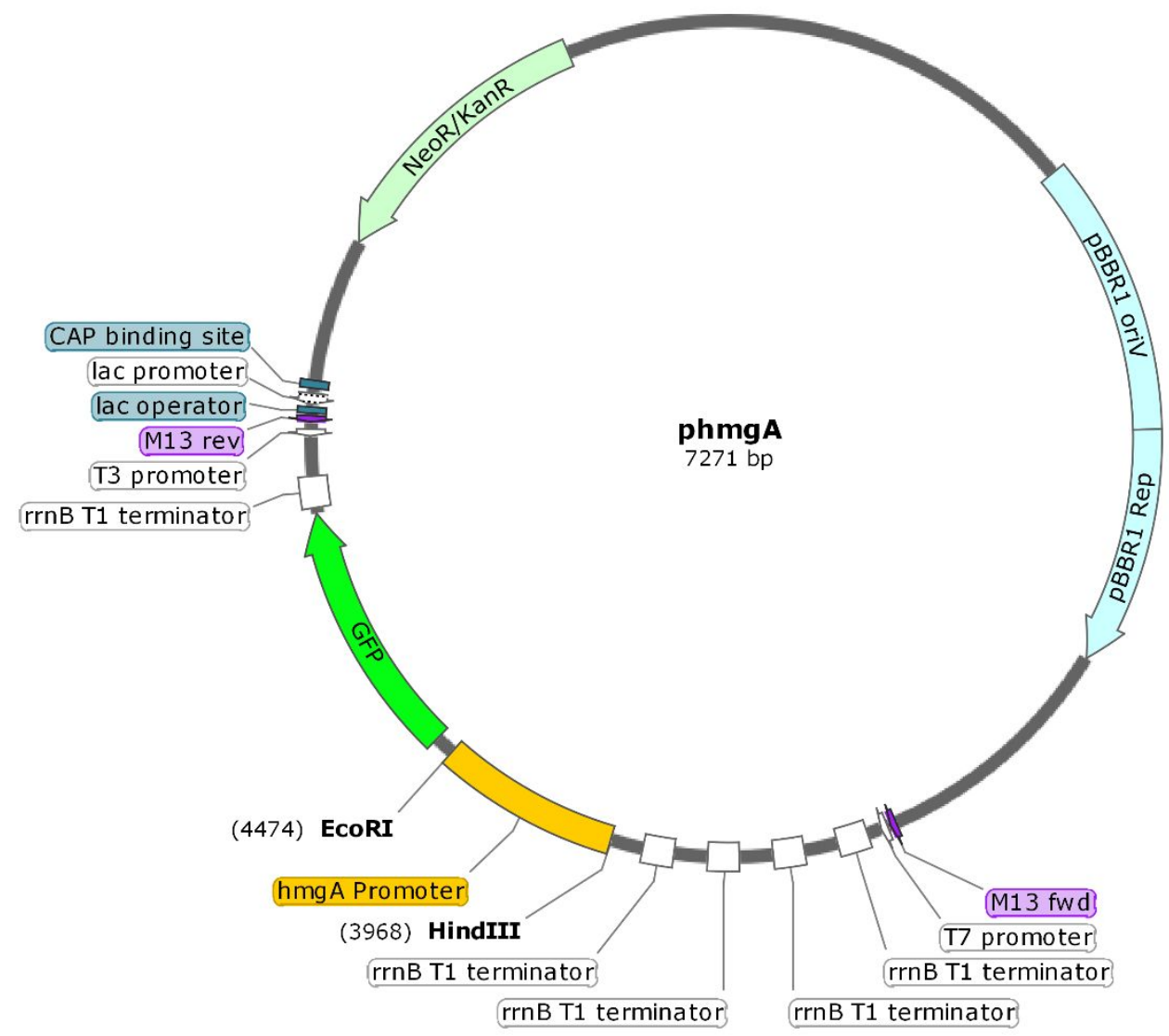

Figure. S2. Construction of phmgA plasmid using restriction enzyme EcoRI and HindIII. Promoter sequence of hmgA gene was transcriptionally fused to Green Fluorescence protein (GFP) in pPROBE-NT plasmid. 


\section{Optimization of fluorescence response for detection of homogentisic acid-}

Overnight culture of phmgA::GFP was subcultured (1\% inoculum) in LB media and kept under shaking conditions at $37{ }^{\circ} \mathrm{C} .2 \%$ culture aliquot were then transferred in minimal media containing a mixture of amino acids without the addition of phenylalanine and tyrosine and $0.4 \%$ glucose. Our results show that an increase in the fluorescence response of homogentisic acid-based biosensor was observed only in assay solution supplemented with a mixture of amino acids but not in glucose-containing media. This suggests that carbon source supplemented in the form of amino acids activates the peripheral pathway involved in the degradation of phenylalanine where homogentisic acid acts as a central intermediate.

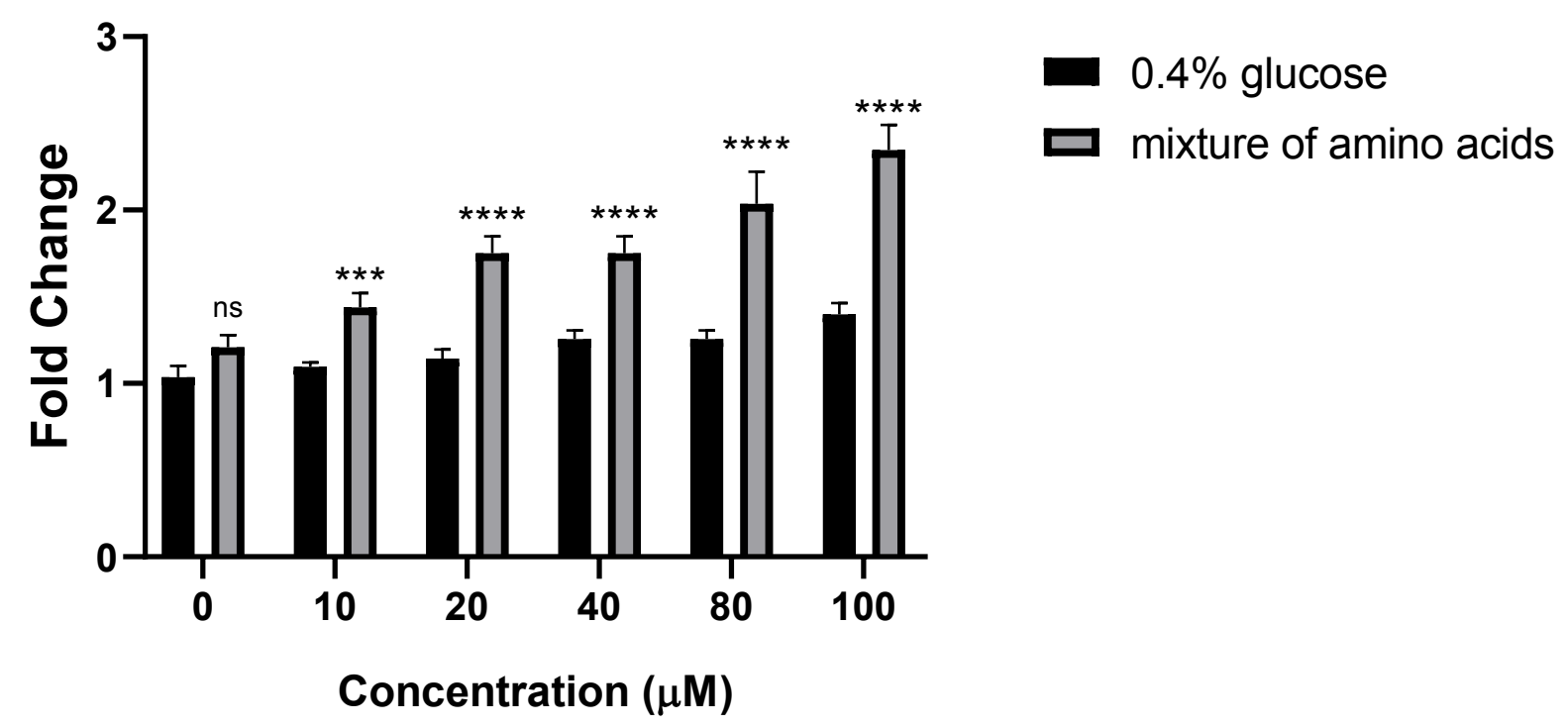

Figure. S3. Optimization of fluorescence response for detection of homogentisic acid in MPAO1 strain. Dose-dependent fluorescence response of phmgA::GFP was measured in $0.4 \%$ glucosecontaining minimal media and minimal media containing a mixture of amino acids. Fluorescence 
response was measured in relative fluorescence unit (RFU) and was divided by the optical density to correct for variation in cell density at a wavelength of $600 \mathrm{~nm}$. Error bars represent the standard deviation of the mean of three independent experiments. Results were analyzed with Two-way ANOVA by comparing the mean of each column with the mean of the other column in that row. $* * * * \mathrm{P} \leq 0.0001, * * * \mathrm{P} \leq 0.001, \mathrm{~ns}-$ not significant. 
4. Comparison between the fluorescence response of wild type MPAO1 strain and Tn::hmgA mutant in response to homogentisic acid.

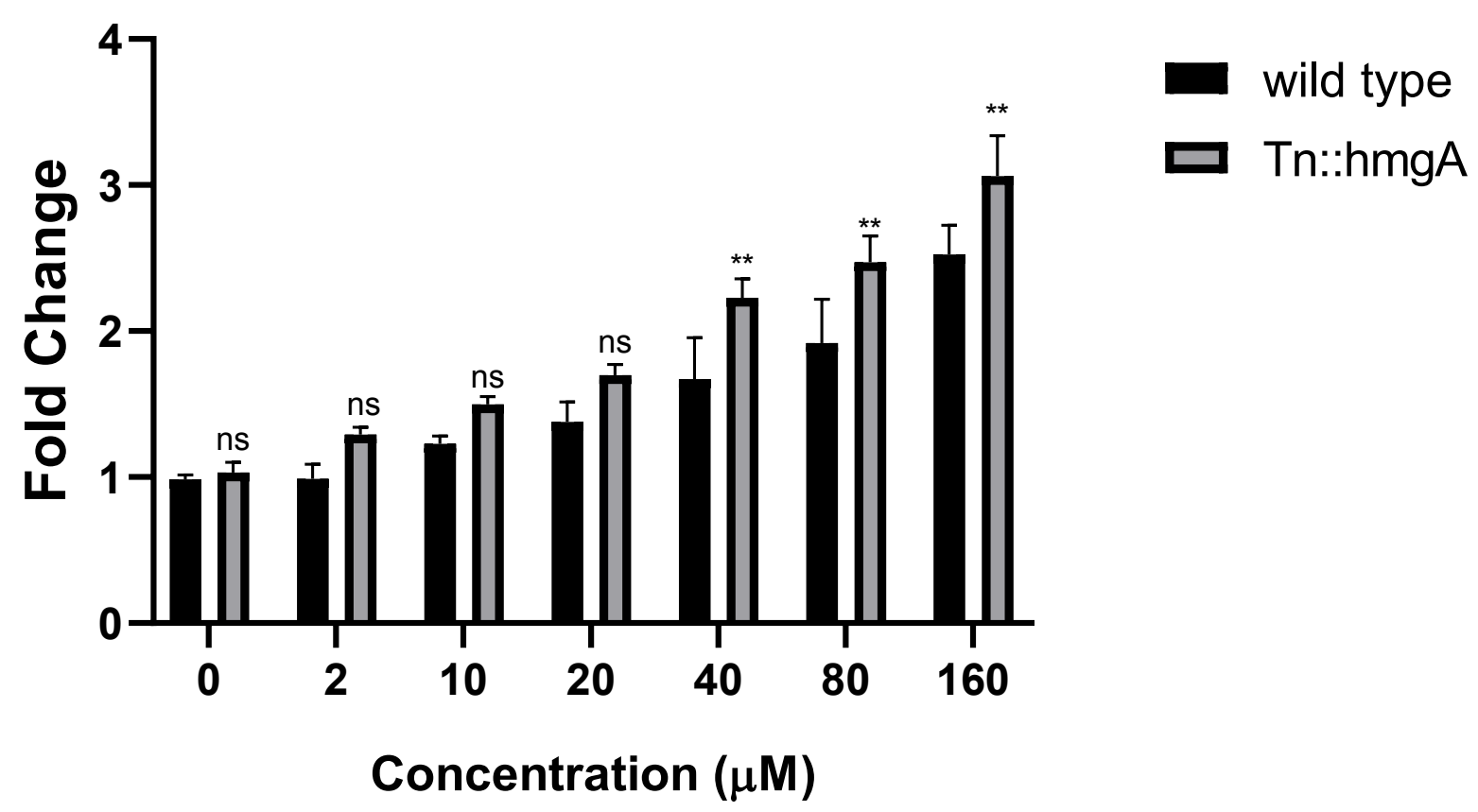

Figure. S4. Comparison between the fluorescence response of wild type MPAO1 strain and Tn::hmgA mutant in response to homogentisic acid at a concentration range from $2 \mu \mathrm{M}$ to 160 $\mu \mathrm{M}$. Error bars represent the standard deviation of the mean of three independent experiment. Results were analyzed with Two-way ANOVA by comparing each cell mean with the other cell mean in that row. ${ }^{*} \mathrm{P} \leq 0.01$, ns - not significant. 
Table S1 -Comparison of Limit of detection of a whole cell based alkaptonuria detection method with other analytical methods and commercial kit.

Detection method

Color-based by addition of

$\mathrm{NaOH}$

Capillary electrophoresis method

LC-MS/MS

FT-IR

Commercial detection kit for alkaptonuria detection.(Tyrosine based assay kit;

Abcam,Cambridge,UK)
$1 \mathrm{mM}^{*}$

$3.3 \mu \mathrm{M}$

$30 \mu \mathrm{M}^{*}$

$2 \mathrm{mM}$

$50 \mu \mathrm{M}$

Abcam

(Cat.\#185435)

Whole cell biosensor

$3.9 \mu \mathrm{M}$

This study

\footnotetext{
${ }^{*}$ Represents limit of Quantification
} 


\section{Quantification of homogentisic acid using HPLC and phmg A::GFP plasmid-based whole-cell biosensor.}

Quantification of homogentisic acid by HPLC method- Quantification of homogentisic acid in urine was analyzed by the previously described method by Bory et al $1990 .{ }^{5}$

4- amino- 2 chlorobenzoic acid was used as an internal standard. The calibrated plot was generated with respect to the peak height ratio $-A_{c} / A_{\text {is }}\left(A_{c}\right.$ stands for peak height for different concentration of homogentisic acid and $\mathrm{A}_{\text {is }}$ stand for peak height for the internal standard) and concentration ratio $-\mathrm{C}_{\mathrm{c}} / \mathrm{C}_{\text {is }}\left(\mathrm{C}_{\mathrm{c}}\right.$ stands for different concentration of homogentisic acid used to generate the calibration plot and $\mathrm{C}_{\text {is }}$ stands for concentration of internal standard). For the unknown concentration of homogentisic acid in spiked urine samples, the peak height of the analyte (homogentisic acid), the internal standard were measured and the ratio was determined to know the concentration of homogentisic acid present in the spiked urine samples. ${ }^{6} \mathrm{~A}$ linear curve having an $\mathrm{R}^{2}$ value of 0.999 was obtained (Figure S5a). To get the unknown concentration of homogentisic acid spiked in a urine sample the height of the homogentisic acid and internal standard were measured and the ratio was determined, which was then used to determine homogentisic acid concentration in the urine sample.

a

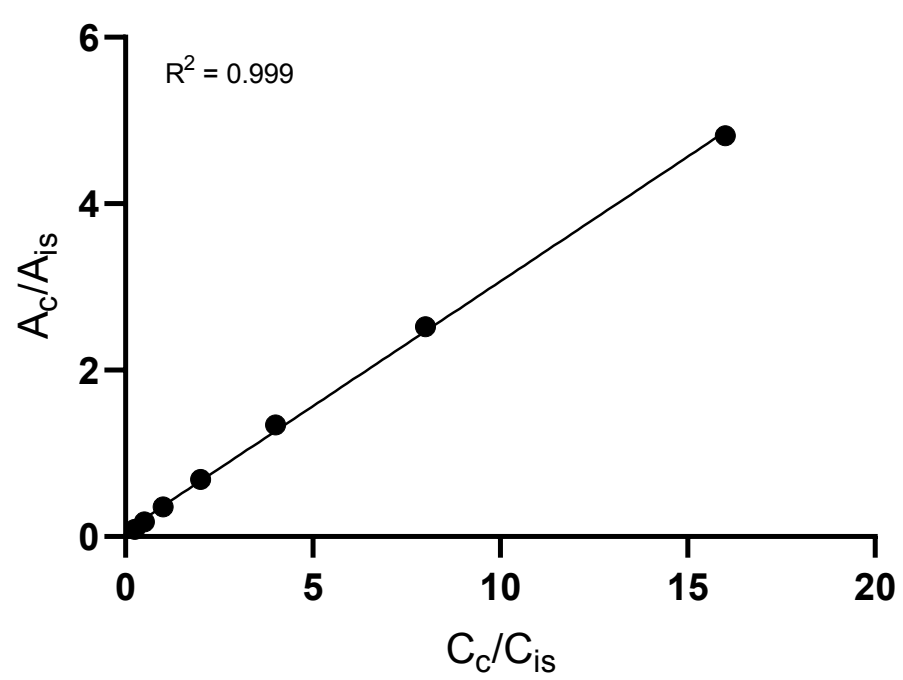

b

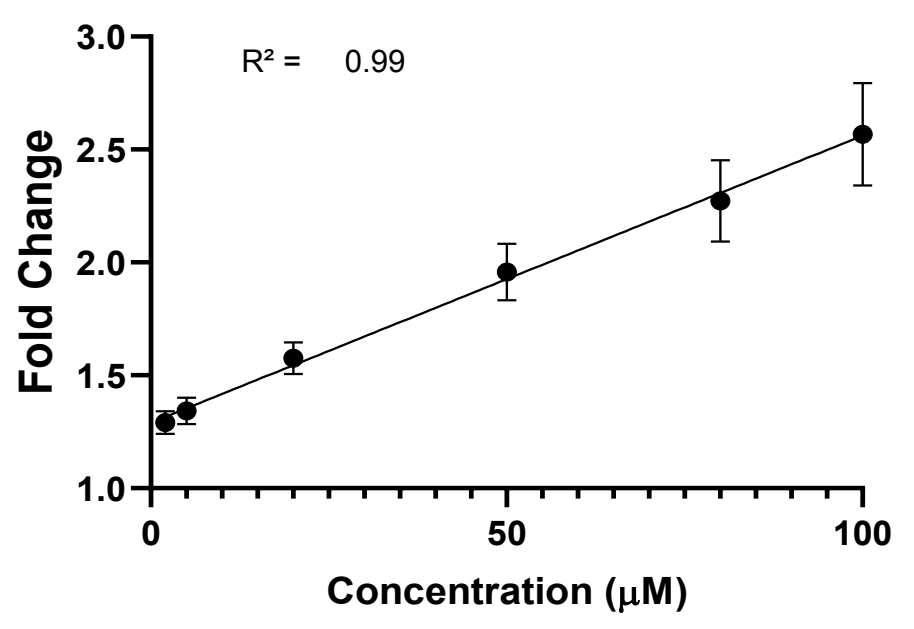

Figure. S5. Linear response of homogentisic acid was determined using a) conventional HPLC and b) phmgA::GFP based whole-cell biosensor. 
Table S2 - Comparison of the cell-based assay with HPLC for detection of homogentisic acid in alkaptonuria patients. SD, standard deviation, $\mathrm{CV}$, coefficient of variation.

\begin{tabular}{llllll}
\hline & $\begin{array}{l}\text { Actual } \\
(\mu \mathrm{M})\end{array}$ & $\begin{array}{l}\text { Measured } \\
(\mu \mathrm{M})\end{array}$ & SD & CV $(\%)$ & Recovery $(\%)$ \\
& $($ HPLC) & $\begin{array}{l}\text { (whole cell- } \\
\text { biosensor) }\end{array}$ & & & \\
\hline Sample 1 & 89.9 & 98.4 & 8.9 & 9.0 & 109.4 \\
Sample 2 & 78.5 & 84.5 & 5.86 & 6.98 & 107.6 \\
Sample 3 & 48.5 & 62.2 & 1.67 & 2.66 & 128.8 \\
Sample 4 & 103.2 & 94.4 & 4.45 & 4.71 & 91.4 \\
Sample 5 & 20.9 & 19.6 & 3.34 & 16.9 & 93.7 \\
Sample 6 & 83.9 & 78.34 & 1.67 & 2.13 & 93.3 \\
Sample 7 & 45.1 & 50.1 & 5.01 & 10.02 & 111.08 \\
Sample 8 & 54.46 & 55.44 & 7.3 & 13.2 & 101.7 \\
Sample 9 & 105.7 & 100.8 & 6.3 & 6.25 & 95.3 \\
Sample 10 & 74.1 & 77.2 & 6.1 & 7.9 & 104.1 \\
\hline
\end{tabular}


Table S3 -Bacterial strains used in this study.

\begin{tabular}{|c|c|c|c|c|}
\hline Bacterial strains & Plasmid used & Genotype & Abbrevations & References \\
\hline PAO1 & $h m g A:: G F P$ & Wild type $P$. aeruginosa $P A O 1$ & PAO1 & 7 \\
\hline MPAO1 & $h m g A:: G F P$ & $\begin{array}{l}\text { Wild type } P \text {. aeruginosa } \\
\text { MPAO1 }\end{array}$ & MPAO1 & \\
\hline SNR 01 & $h m g A: \because G F P$ & $\begin{array}{l}\text { PA0872:: ISphoA/hah derivative } \\
\text { of MPAO1 strain }\end{array}$ & Tn::phhA & 8 \\
\hline SNR 02 & $h m g A \because G F P$ & $\begin{array}{l}\text { PA0870:: ISlacZ/hah derivative } \\
\text { of MPAO1 strain }\end{array}$ & Tn:: phhC & 8 \\
\hline SNR 03 & $h m g A: \because G F P$ & $\begin{array}{l}\text { PA } 0865:: \text { ISlacZ/hah } \\
\text { derivative of MPAO1 strain }\end{array}$ & Tn::hpd & 8 \\
\hline SNR 04 & $h m g A: \because G F P$ & $\begin{array}{l}\text { PA } 2009:: \text { ISphoA/hah } \\
\text { derivative of MPAO1 strain }\end{array}$ & Tn:: hmgA & 8 \\
\hline
\end{tabular}




\section{References}

1. Jacomelli, G.; Micheli, V.; Bernardini, G.; Millucci, L.; Santucci, A., Quick diagnosis of alkaptonuria by homogentisic acid determination in urine paper spots. In JIMD Reports, Volume 31, Springer: 2016; pp 51-56.

2. Oztekin, N.; Balta, G. S.; Cansever, M. S., Determination of homogentisic acid in urine for diagnosis of alcaptonuria: Capillary electrophoretic method optimization using experimental design. Biomed Chromatogr 2018, 32 (7), e4216.

3. Hughes, A. T.; Milan, A. M.; Christensen, P.; Ross, G.; Davison, A. S.; Gallagher, J. A.; Dutton, J. J.; Ranganath, L. R., Urine homogentisic acid and tyrosine: simultaneous analysis by liquid chromatography tandem mass spectrometry. J Chromatogr B Analyt Technol Biomed Life Sci 2014, 963 , 106-12.

4. Markus, A. P. J. A.; Swinkels, D. W.; Jakobs, B. S.; Wevers, R. A.; Trijbels, J. M. F.; Willems, H. L., New technique for diagnosis and monitoring of alcaptonuria: quantification of homogentisic acid in urine with mid-infrared spectrometry. Analytica Chimica Acta 2001, 429 (2), 287-292.

5. Bory, C.; Boulieu, R.; Chantin, C.; Mathieu, M., Diagnosis of alcaptonuria: rapid analysis of homogentisic acid by HPLC. Clin. Chim. Acta 1990, 189 (1), 7-11.

6. Dolan, J. W., When should an internal standard be used. LCGC N. Am, (2012), 30(6), 474.

7. Stover, C. K.; Pham, X. Q.; Erwin, A. L.; Mizoguchi, S. D.; Warrener, P.; Hickey, M. J.; Brinkman, F. S.; Hufnagle, W. O.; Kowalik, D. J.; Lagrou, M.; Garber, R. L.; Goltry, L.; Tolentino, E.; Westbrock-Wadman, S.; Yuan, Y.; Brody, L. L.; Coulter, S. N.; Folger, K. R.; Kas, A.; Larbig, K.; Lim, R.; Smith, K.; Spencer, D.; Wong, G. K.; Wu, Z.; Paulsen, I. T.; Reizer, J.; Saier, M. H.; Hancock, R. E.; Lory, S.; Olson, M. V., Complete genome sequence of Pseudomonas aeruginosa PAO1, an opportunistic pathogen. Nature 2000, 406 (6799), 959-64.

8. Jacobs, M. A.; Alwood, A.; Thaipisuttikul, I.; Spencer, D.; Haugen, E.; Ernst, S.; Will, O.; Kaul, R.; Raymond, C.; Levy, R.; Chun-Rong, L.; Guenthner, D.; Bovee, D.; Olson, M. V.; Manoil, C., Comprehensive transposon mutant library of Pseudomonas aeruginosa. Proc Natl Acad Sci U S A 2003, 100 (24), 14339-44. 